\title{
Where can tourism-led growth and economy-driven tourism growth occur? ${ }^{1}$
}

\author{
Vera Shanshan Lin \\ shanshanlin@zju.edu.cn \\ School of Management, Zhejiang University, Hangzhou, China \\ Yang Yang \\ yangy@temple.edu \\ School of Tourism and Hospitality Management, Temple University, USA \\ Gang Li* \\ g.li@ surrey.ac.uk \\ School of Hospitality and Tourism Management, University of Surrey, UK
}

\begin{abstract}
In this study, we investigate the causal relationships between international tourism growth and regional economic expansion in China, and more importantly, disclose the factors determining the occurrence of these relationships. The empirical results reveal that 10 out of 29 regions experienced tourism-led growth (TLG) during 1978 to 2013, whereas nine regions experienced economy-driven tourism growth (EDTG). Different from the past literature, this study uses Bayesian probit models to unveil the factors influencing these different growth patterns. Our results suggest that regions with less-developed economies, larger economic sizes, and covering larger geographic areas are more likely to experience TLG, and regions with less-developed economies are more likely to experience EDTG as well. Lastly, practical implications are provided.
\end{abstract}

Keywords: tourism-led growth; economy-driven tourism growth; Toda-Yamamoto Granger causality test; Bayesian bivariate probit model

\footnotetext{
${ }^{1}$ The paper should be cited as follows:

Lin, V. S., Yang, Y. and Li, G. (2018). Where can tourism-led growth and economy-driven tourism growth occur? Journal of Travel Research, 1-13. DOI: 10.1177/0047287518773919

*Corresponding Author: Gang Li, School of Hospitality and Tourism Management, University of Surrey, Guildford, Surrey, GU2 7XH, UK; Tel.: +44 (0)1483 686356; Fax: +44 (0)1483 689511; Email: g.li@ surrey.ac.uk
} 


\section{INTRODUCTION}

As a service industry that attracts capital investment (de la Mata and Llano-Verduras 2012), creates employment opportunities (Fawaz, Rahnama, and Stout 2014), stimulates foreign exchange earnings (Balaguer and Cantavella-Jordá 2002), and facilitates innovation transfers (Weidenfeld 2013), tourism has long been recognized as a significant contributor to local economies (Brida, Cortes-Jimenez, and Pulina 2016; Castro-Nuño, Molina-Toucedo, and Pablo-Romero 2013). The economic benefits created by the tourism industry also spill over into other economic sectors through various backward- and forward- linkages. Owing to its substantial multiplier effect, local governments and members of society support tourism development to improve economic conditions and boost employment opportunities. Moreover, some induced economic benefits concomitant with tourism growth include burgeoning investments in public infrastructure, extended openness to foreign investment, and poverty reduction. Numerous empirical studies have confirmed that developing a flourishing tourism industry invigorates local economies and improves the living standards of local residents (Cárdenas-García, Sánchez-Rivero, and PulidoFernández 2015).

Recognizing the tourism industry as a catalyst for economic growth, Balaguer and CantavellaJordá (2002) proposed the tourism-led growth (TLG) hypothesis, which postulates a unidirectional causal relationship between international tourism expansion and economic growth. This pioneering paper triggered substantial research interest in the nexus between tourism expansion and economic growth, and empirical efforts to validate the TLG hypothesis are ongoing (Brida et al. 2016; del P. Pablo-Romero and Molina 2013). At the same time, local economic expansion likely facilitates tourism growth by attracting business travelers and improving physical and human capital, such as infrastructure, health, and education (Eugenio-Martin, Martín-Morales, and Sinclair 2008). This causal relationship, embedded in the economy-driven tourism growth (EDTG) hypothesis, has been empirically confirmed in several studies (Cortés-Jiménez, Nowak, and Sahli 2011; Oh 2005; Payne and Mervar 2010).

According to a systematic and in-depth survey by Brida et al. (2016), the TLG hypothesis has been confirmed by a number of empirical studies, but rejected in several countries. In another review, del P. Pablo-Romero and Molina (2013) found that the TLG hypothesis has been rejected in at least 13 studies. These mixed and inconclusive results for different countries indicate that further research is needed to investigate country-specific factors influencing the occurrence of TLG. Tang and Jang (2009) explained that the inconsistent results of the tourism-economy relationship might be a reflection of the country effect which could be attributed to nation-specific factors such as the weight of tourism in the overall economy, the size and openness of the economy, and the production capacity constraints. Furthermore, Cárdenas-García, Sánchez-Rivero, and PulidoFernández (2015) showed that the relationship between tourism and economic growth can be different for countries at different development levels. Since most researchers have focused primarily on a single country or region, it is difficult to compare and evaluate the results across different studies. First, tourism-related variables might be measured inconsistently across different national statistical systems. For instance, according to United Nations World Tourism Organization (UNWTO, 2017) and Wu, Song and Shen (2017), visitor arrivals, tourist arrivals (excluding same-day visitors), tourist arrivals at hotels and similar establishments, nights of tourists in hotels and similar establishments are used by different countries to record international tourist arrivals statistics. Second, as argued by del P. Pablo-Romero and Molina (2013), the results 
of TLG tests are sensitive to the specifications of econometric models; therefore, the substantial diversity that exists among model specifications in past studies impedes further comparisons and synchronization of the empirical results. To the best of our knowledge, despite the existence of a large number of studies investigating the nexus between tourism expansion and economic growth, researchers have not yet empirically investigated the factors explaining the existence of TLG or EDTG based on rigorous econometric analysis and statistical evidence. In a comparable term, why may TLG or EDTG take place in some countries or regions, but not the others? Under what conditions may TLG or EDTG occur? These research questions are yet to be answered.

This study aims to fill the above research gap in the TLG literature by employing a two-step modeling approach. Based on the first-step causality test results with a sample of 29 Chinese provincial regions using annual data from 1978 to 2013, a Bayesian bivariate probit model is used in the second step to identify the determinants of TLG and EDTG trajectories for these regions. We aim to contribute to the current debate over the TLG hypothesis and the economic underpinnings of TLG and EDTG by comparing causality results across different regions within a single country. We select China as the setting for our case study because it has the fourth-largest tourism market worldwide from 2012 onwards in terms of the visitor volume: in 2016, international arrivals reached 59.3 million, and international tourism revenue totaled USD 44.4 billion (UNWTO, 2018). Unlike previous research focusing on a single country/region, we test the TLG and EDTG hypotheses using annual data from 29 provincial regions in China. The statistical results are directly comparable since a common econometric method is applied, the same statistical measurements are used, and all the regions in the sample are from the same economic, political and cultural system within a single country. Based on the Toda-Yamamoto (T-Y) Granger causality test, we utilize Bayesian bivariate/univariate probit models to unveil the factors explaining the four types of causality results: no causality, unidirectional causality from tourism expansion to economic growth (TLG), unidirectional causality from economic growth to tourism expansion (EDTG), and bi-directional causality between the two (TLG and EDTG). Bayesian inference is particularly useful in our context of a small sample to generate finite-sample results based on posterior distribution (Rossi, Allenby, and McCulloch 2012). In summary, this study attempts to shed light on the factors explaining which growth pattern is likely to take place by using advanced econometric methods, and the results are expected to provide scientific evidence to policymakers in formulating appropriate strategic plans to facilitate tourism development.

\section{LITERATURE REVIEW AND HYPOTHESIS DEVELOPMENT}

\subsection{Tourism-led growth}

The theoretical background of the TLG hypothesis is rooted in a conventional export-led growth hypothesis that highlights the vital role of export expansion in stimulating economic growth. Exports contribute to economic growth by diffusing technological knowledge, improving production allocation efficiency, and achieving economies of scale and scope (Brida et al. 2016). Regarded as a particular type of export, international tourism helps accumulate foreign exchange earnings, which are vital to import the goods necessary for production in other economic sectors (Castro-Nuño et al. 2013). Through these mechanisms, international tourism is likely to facilitate economic growth. 
Moreover, as an exogenous part of aggregate demand, international tourism is expected to have a positive effect on national income, and subsequently on employment through Keynesian multiplier effects (Seetanah 2011). As suggested by neoclassical growth theory, some countries specialize in tourism to remedy other competitive disadvantages, such as technological deficiency (Brida et al. 2016). In addition, tourism can facilitate the use of resources that are in line with the factor endowment of a country, improve a country's infrastructure, help transfer new technological and managerial skills into an economy, and possibly help create positive linkages with other sectors of the economy including agriculture, manufacturing and other service industries (Modeste 1994, cited in Ridderstaat, Croes, and Nijkamp 2014). The TLG hypothesis has been examined in a large body of empirical literature through the use of various econometric methods (Cárdenas-García and Sánchez-Rivero 2015; Castro-Nuño et al. 2013). Notably, Castro-Nuño et al. (2013) conducted a meta-analysis based on panel data studies on the TLG hypothesis, and their results confirm the contribution of tourism to economic growth.

However, the TLG hypothesis has been rejected in several countries such as Croatia (Payne and Mervar 2010), Cyprus (Katircioglu 2009), Korea (Oh 2005), Tunisia (Cortés-Jiménez et al. 2011), Malta and Egypt (Aslan 2013), and the United States (Tang and Jang 2009). Figini and Vici (2010) showed that even though tourism boosted national economic growth in the 1980s, tourism's stimulation effect worldwide was no longer significant after 1990. Several plausible reasons could explain the lack of TLG in particular countries/regions. Applying a dynamic trade model with four agents, Albaladejo Pina and Martínez-García (2013) found that as an endogenous factor, the quality of tourist services is important in maintaining tourism's role in promoting long-term growth. Another stream of research highlights that the economic stimulation injected by the tourism industry can be transitional, and a high level of tourism specialization can impede long-term economic growth (Lanza, Temple, and Urga 2003).

Lanza et al. (2003) and Algieri (2006) suggested that the amount of economic benefit derived from the tourism industry depends on the magnitude of substitution elasticity between tourism and other goods/services. Recently, Cárdenas-García et al. (2013) proposed a theoretical framework for understanding the influence of tourism growth on economic expansion from economic, environmental and sociocultural perspectives. The significant contribution of tourism to economic growth occurs only when those benefits outweigh the corresponding costs. Lastly, Ma, Hong, and Zhang (2015) suggested that even though local tourism helps facilitate economic growth, it does not shrink economic disparities between different regions due to the polarizing effect that expands gaps between tourism clusters.

Others have found that tourism growth may have a negative impact on welfare under certain conditions (Copeland 1991). The Dutch Disease effect could be an important danger leading to distortion of the real exchange rate and de-industrialization (Chao, Hazari, Laffargue, Sgro, and $\mathrm{Yu}$ 2006). Tourism also could reduce the welfare of local citizens due to trade distortion stemming from inappropriate export taxes and/or import subsidies (Chen and Devereux 1999). With a general equilibrium analysis of the effects of tourism on other economic sectors, Nowak, Sahli, and Sgro (2003) also found that welfare and manufacturing output may fall as a result of increased tourism under certain conditions. Nowak and Sahli (2007) argued that the symptoms of Dutch Disease may 
also result from tourism demand shocks, with welfare reduction stemming from labor losses and intense tourism-related land use.

Although it has been recognized as a potential economic development strategy, tourism is not always a panacea for economic growth; only under certain geographic and socio-economic circumstances can tourism growth contribute to economic prosperity (Cárdenas-García and Sánchez-Rivero 2013; Cárdenas-García et al. 2013; Fawaz et al. 2014; Ivanov and Webster 2013). First, a threshold level of economic development should be achieved before a country develops tourism (Eugenio-Martin et al. 2008). Fawaz et al. (2014) found that in low-income countries, the impact of international tourism on spurring economic growth is insignificant due to an insufficient level of infrastructure support. Second, Cárdenas-García and Sánchez-Rivero (2013) highlighted the importance of geographic features and appropriate infrastructure in transferring tourism expansion into economic growth. Through an empirical analysis of 144 countries, they found that the TLG hypothesis is not supported in the least-developed countries, and that undesirable geographic features and a lack of infrastructure impede the channeling of tourism earnings toward economic growth. Third, del P. Pablo-Romero and Molina (2013) conducted a thorough review of the empirical literature on TLG and highlighted that the relationship between tourism and economic growth in a country hinges on several factors, including the country's degree of specialization in tourism. Although tourism specialization leads to faster economic growth in small countries (Brau, Lanza, and Pigliaru 2007) and contributes to TLG (Oh 2005), the relationship between tourism specialization and economic growth can be non-linear. Adamou and Clerides (2010) found that tourism has little or even a negative impact on economic growth at high levels of specialization. This argument on the diminishing impact of tourism specialization was further empirically supported by Chang, Khamkaew, and McAleer (2012). Moreover, over-dependence on the tourism industry can be detrimental for sustainable economic growth for at least two reasons (Parrilla, Font, and Nadal 2007): (a) the depreciation of natural resources leads to economic deterioration over the long term; and (b) qualified human capital is scarce in tourism-dependent economies, making it difficult to increase labor productivity, and thus slowing down the economic growth (Parrilla et al. 2007).

However other scholars have found that only countries with low levels of economic development can experience TLG. Taking advantage of unique tourism-related resource endowments can be a reasonable economic development strategy for nations with limited capital assets (Yang and Fik 2014). Empirical evidence shows that developing countries always benefit from tourism specialization (Sequeira and Maçãs Nunes 2008). Using a growth decomposition method, Ivanov and Webster (2013) calibrated the impact of tourism on economic growth in 174 countries and found that the impact is highest in Africa, Asia, Latin America and the Caribbean, areas with many less-developed countries. Eugenio-Martín, Martín Morales, and Scarpa (2004) studied the relationship between tourism and economic growth in Latin American countries and suggested that tourism development contributes to national economic growth in countries with a low level of gross domestic product (GDP) per capita. Based on the findings in the literature, we propose our first research hypothesis as follows:

H1: Regions with less-developed economies are more likely to experience tourism-led growth. 
After recognizing the mixed results of the causality direction between tourism and economic growth, Kim, Chen, and Jang (2006) suggested that size of an economy can be a determinant of this causality. Sequeira and Maçãs Nunes (2008) found empirical evidence that tourism's contribution to economic growth decreases once small countries are included in the econometric model, indicating that a small local economy impedes tourism's economic stimulation. Moreover, in several studies, researchers identified a larger economic multiplier of tourism in larger economies (Pratt 2011; van Leeuwen, Nijkamp, and Rietveld 2009). Huse, Gustavsen, and Almedal (1998) argued that a large economic base can provide more diversified economic structure, and as a result, tourism overflows can be more readily absorbed by forward- and backward-linked industries. A diversified economy also enables the tourism industry to connect to suitable local suppliers, thereby boosting the local economy to a larger degree (Robles Teigeiro and Díaz 2014; van Leeuwen et al. 2009). To investigate the relationship between economic size and TLG, we propose the following hypothesis:

\section{H2: Regions with larger economies are more likely to experience tourism-led growth.}

The geographic area of a region determines its potential to offer a wealth of natural and cultural resources to cater to a wide variety of needs from incoming tourists. According to Lanza and Pigliaru (2000), the relative endowment of natural resources determines the degree to which small economies specialize in tourism and experience the associated fast economic growth. More importantly, according to Luo, Yan, and Yang (2016), Chinese provincial regions covering larger geographic areas tend to have more diverse tourist attractions. As suggested by the first law of geography (i.e., distance decay theory), near things are more related than distant things (McKercher, Chan, and Lam 2008). Therefore, within a geographically large provincial region, those destinations relatively distant from each other within the region are likely to offer different tourist experiences, making the whole region more attractive to tourists as a bundle of diverse tourism products. This variety of attractions can motivate tourists to stay longer and spend more (Leones, Colby, and Crandall 1998), resulting in massive injections of capital into the local economy. Moreover, a wide variety of attractions reduces and mitigates the seasonality of tourist activities because more destinations are likely to be interesting to tourists at different times throughout the year (Claver-Cortés, Molina-Azori'n, and Pereira-Moliner 2007). In turn, reduced seasonality alleviates the problem of low-efficiency use of inflexible resources during off-peak seasons and improves a region's ability to sustain economic benefits of tourism in the long run (Koenig-Lewis and Bischoff 2005). Hence, we propose the following hypothesis:

\section{H3: Regions covering larger geographic areas are more likely to experience tourism-led growth.}

\subsection{Economy-driven tourism growth}

Natural resources are not enough to achieve sustainable tourism growth (Croes 2011); local economic growth plays a key role in facilitating local tourism development (Eugenio-Martin et al. 2008). As countries experience economic growth and expansion, the concomitant boost in international trade contributes to an increasing number of international arrivals in the form of business travelers (Oh 2005). Moreover, economic expansion leads to increasing physical and human capital and a nurturing economic environment that proliferates tourism growth (Antonakakis, Dragouni, and Filis 2015). In particular, economic growth improves tourism-related infrastructure and service quality (Eugenio-Martin et al. 2008) through spillover effects from other 
economic sectors (Capone and Boix 2008). More specifically, the investment in some transport infrastructure can be vital to tourism growth (Khadaroo and Seetanah 2007). Lastly, a high level of economic development is associated with a better educational system, which provides sufficient skilled labor to the tourism industry (Eugenio-Martin et al. 2008), thereby enhancing the competitiveness of the destination. In some empirical studies, researchers found a unidirectional causal relationship between local economic expansion and tourism growth, whereas others even suggested a reciprocal relationship between them (Durbarry 2004; Kim et al. 2006). However, the EDTG hypothesis is not always supported due to different economic conditions of tourism destinations (Balaguer and Cantavella-Jordá 2002; Gunduz and Hatemi-J 2005; Lee and Chang 2008).

Yang and Fik (2014) found empirical evidence of a catch-up effect in regional tourism growth: regions with less-developed tourism industries experience faster tourism growth as they attempt to catch up with the leading regions. A better understanding of the nexus between tourism specialization and economic growth is crucial in a resource-scarce environment as it can provide insightful information as to policies to be implemented: to allocate more resources to the tourism industry aimed at obtaining higher levels of economic growth in the future, or to allocate funds to other tourism-related industries by channeling funds to tourism-related activities. Ridderstaat, Croes, and Nijkamp (2014) found a bilateral causality between tourism development and economic growth in a small island destination (i.e., Aruba), suggesting that tourism is not only an engine for long-term economic growth, but the economic outcome can be an important impetus to provide long-run growth potential to tourism. Recognizing the economic benefits of the tourism industry, those regions with more depressed tourism economies are more motivated to develop tourism by leveraging and allocating existing resources to the tourism sector due to demonstration effects and knowledge transfers from regions where the tourism industry is more developed (Yang and Wong 2012). Therefore, we propose the following research hypothesis:

\section{H4: Less tourism specialized regions are more likely to experience economy-driven tourism growth.}

Less developed regions generally lack well-developed secondary sectors (e.g., manufacturing industries); thus tourism has a comparative advantage (Belay 2007). Also, compared to manufacturing industries, tourism requires relatively lower levels of capital and technology inputs. Hence, it is relatively easier to develop and tends to be chosen as an economic strategy for poverty reduction (Croes and Vanegas 2008). Less-developed regions are more willing to allocate the capital assets gained through their economic expansion to support tourism growth in order to leverage the benefits from tourism specialization that are available specifically to under-developed economies (Sequeira and Maçãs Nunes 2008). Therefore, we propose the following research hypothesis:

H5: Regions with less-developed economies are more likely to experience economy-driven tourism growth.

Tourism, especially international tourism, imposes a substantial demand on high-quality infrastructure to cater to tourists' needs to provide a comprehensive experience of traveling (Akinboade and Braimoh 2010). Oh (2005) studied the relationship between gross domestic 
product (GDP) and aggregate tourism receipts, and discovered a one-way causal relationship for EDTG in South Korea. Oh (2005) further argued that the rapid economic expansion in South Korea tend to attract more international travel and lead to an increase in tourism growth. Consistent with Oh's (2005) findings, Tang and Jang (2009) identified a uni-directional causality from GDP to four tourism industries (i.e. airline, casino, hotel, and restaurant industries), suggesting that tourism industries in the USA generally benefitted from economic development in the short term but lacked a long-term equilibrium with the economy. Based on Taiwan's GDP and total tourist arrivals, Kim et al. (2006) obtained opposite findings from those of Oh (2005), i.e., the long-run equilibrium and a reciprocal relationship between economic development and tourism expansion were identified. They explained that the difference may arise from the size of the economy: Taiwan is a smaller economy than South Korea and thus is more sensitive to tourism fluctuations. Findings from Kim et al. (2006) and Tang and Jang (2009) indicate that a larger economy is more likely to support the EDTG hypothesis. Economies of scale play a dominant role in stimulating EDTG. For the tourism business, owing to scale economies, efficiency is also greater with increasing scale, leading to a lower variable cost (Zhang and Jensen 2007). In a region with a large economic base, the scale economies are more likely to achieve, and because of external economies, many facilities and infrastructure that are not specifically designed for tourism become available to incoming tourists (Capone and Boix 2008). Hence, the relationship between economic size and EDTG can be proposed in the following hypothesis:

H6: Regions with a larger size of the local economy are more likely to experience economy-driven tourism growth.

\section{METHODOLOGY}

We adopt a two-step approach to empirical analysis. While the first-step analysis involves time series analysis to gauge the occurrences of TLG and EDTG of each provincial region after stationarity, cointegration and causality tests, the second-step analysis is cross-sectional by its nature to investigate factors explaining the occurrences of TLG and EDTG using Bayesian bivariate probit models.

\subsection{Stationarity, cointegration, and causality tests}

We first use several stationarity, cointegration, and causality tests to test the TLG and EDTG hypotheses for each provincial region. We selected two key variables: one measuring tourism development and the other measuring economic growth. The measurements adopted in this study are in line with the majority of past literature (Corrie, Stoeckl, and Chaiechi 2013). The tourism revenue series $(T R)$ is international tourism revenue of the provincial region in 2010 prices that are adjusted by consumer price index and transformed into the local currency of RMB. We measured economic growth as the real gross domestic product $(R G D P)$ volume in 2010 prices. We used real terms for all variables, which were expressed as natural logarithms using data from 29 provincial regions in China. All data were obtained from the Chinese Tourism Statistical Yearbook and Chinese Statistical Yearbook (1979-2014). We excluded Sichuan province and Chongqing municipal city due to data unavailability and administrative changes. 
To check for the presence of unit roots, we adopted the ERS test proposed by Elliott, Rothenberg, and Stock (1996) and the Ng and Perron test developed by Ng and Perron (2001) to improve the power of the unit root test. We also performed a commonly used stationarity test, the KwiatkowskiPhillips-Schmidt-Shin (KPSS) test to complement the ERS test. After determining the integration order of the series, we used the cointegration model to examine the long-run equilibrium relationships among the relevant variables since time series are non-stationary. More specifically, we employed bounds tests for cointegration-the autoregressive distributed lag (ARDL) modeling approach proposed by Pesaran et al. (2001), which confers the advantage of accommodating variables with different integration orders (Narayan and Narayan 2005). In the model, we included a set of dummy variables to capture the impact of mega-events (e.g., the outbreak of severe acute respiratory syndrome (SARS) in 2003; multiple events in 2008, including the earthquake in Sichuan and visa restrictions before the Olympic Games). We selected optimal lag orders based on the Schwarz Bayesian criterion (SBC) (Pesaran and Shin 1998) and employed the $F$-test and $t$ test to test the null hypothesis of no long-run relationship between two variables.

The Granger causality test (Granger 1988) was designed to determine whether the lag(s) of one variable has a statistically significant influence on another variable. In this study we applied a refined causality test proposed by Toda and Yamamoto (1995) to overcome the pretest biases with the traditional Granger causality test (He and Maekawa 2001; Shan and Wilson 2001) by incorporating extra lags into the model to test hypotheses expressed as restrictions on the parameters of vector autoregressive (VAR) models without pretesting unit roots and cointegrating ranks. We estimated an augmented $\operatorname{VAR}\left(k+d_{\max }\right)$ model, where $k$ indicates the order of integration and $d_{\max }$ is the maximum order of integration that might occur in the process. We could then test linear or nonlinear restrictions on the first $k$ matrices of coefficients using standard asymptotic theory. Since our focal interest was each unit rather than the entire group, we did not employ the panel Granger causality test further.

\subsection{Bayesian bivariate probit model}

We adopted a bivariate probit model consisting of two probit equations to understand the joint determination of two dummy variables, $y_{1}$ and $y_{2}$. Assume there are two latent variables, $y_{1}^{*}$ and $y_{2}^{*}$, such that

$y_{1}^{*}=\mathbf{x}_{1} \beta_{1}+v_{1} ; y_{1}=1$ if $y_{1}^{*}>0 ; y_{1}=0$,otherwise;

$y_{2}^{*}=\mathbf{x}_{2} \beta_{2}+v_{2} ; y_{2}=1$ if $y_{2}^{*}>0 ; y_{2}=0$, otherwise;

$\left(\begin{array}{l}v_{1} \\ v_{2}\end{array} \mid \mathbf{x}_{1}, \mathbf{x}_{2}\right) \sim N(\mathbf{0}, \mathbf{\Sigma})$.

In the model, the disturbance terms $v_{1}$ and $v_{2}$ are assumed to be correlated under a bivariate normal distribution with a variance-covariance matrix $\boldsymbol{\Sigma}$. The association between $y_{1}$ and $y_{2}$ can be captured by the correlation coefficient $\sigma$ in the matrix. To yield the posterior distribution, we first introduced the prior distribution by assuming a normal distribution for $\beta_{1}$ and $\beta_{2}$, and an inverted Wishart distribution for the variance-covariance matrix $\boldsymbol{\Sigma}$ of the error terms. The joint posterior distribution can be written as: 
where $\omega$ represents the latent value of $y$. Since the left-hand side term cannot be estimated analytically, we had to resort to simulation methods to draw a sequence of estimates. Following the procedure documented by Edwards and Allenby (2003), we used Gibbs sampling, a Markov chain Monte Carlo (MCMC) algorithm, to obtain a sequence of observations when a stationary distribution is converged independently from the initial status. With starting values of $\omega_{(0)}, \beta_{(0)}$ and $\boldsymbol{\Sigma}_{(0)}$, the detailed drawing and sampling algorithm is specified as follows:

$\omega_{(1)} \mid \omega_{(0)}, \beta_{(0)}, \boldsymbol{\Sigma}_{(0)}, y \sim N\left(\left(\mathbf{X} \beta_{(0)}-\sigma \gamma^{\prime}\left(\omega_{(0)}-\mathbf{X} \beta_{(0)}\right)\right), \sigma^{-1}\right) \times[I(y=1) I(\omega>0)+I(y=$

0) $I(\omega<0)]$

$\beta_{(1)} \mid \omega_{(1)}, \boldsymbol{\Sigma}_{(0)} \sim N\left(\left(\mathbf{X}^{\prime} \boldsymbol{\Sigma}_{(0)}^{-1} \mathbf{X}+\mathbf{A}\right)^{-1}\left(\mathbf{X}^{\prime} \boldsymbol{\Sigma}_{(0)}^{-1} \omega_{(1)}+\mathbf{A} \bar{\beta}\right),\left(\mathbf{X}^{\prime} \boldsymbol{\Sigma}_{(0)}^{-1} \mathbf{X}+\mathbf{A}\right)^{-1}\right)$

$\boldsymbol{\Sigma}_{(1)} \mid \omega_{(1)}, \beta_{(1)} \sim$ Inverted Wishart $\left(n+g_{0}, \sum\left(\omega_{(1)}-\mathbf{X} \beta_{(1)}\right)^{\prime}\left(\omega_{(1)}-\mathbf{X} \beta_{(1)}\right)+G_{0}\right)$

where $\gamma^{\prime}$ is the row vector of $\boldsymbol{\Sigma}_{(0)}^{-1}, \mathbf{A}$ is specified from the prior distribution of $\beta$, and $g_{0}$ and $G_{0}$ are parameters from the prior distribution of $\Sigma$. After repeating the whole process for a large number of times, we were able to conduct the analysis based on those simulated values after excluding some values simulated at the beginning. This Gibbs algorithm is also applicable to the Bayesian univariate probit model (Rossi, Allenby, and McCulloch 2012). All model estimation procedures were finished by R package 'bayesm' (Bayesian Inference for Marketing/MicroEconometrics).

Bayesian inference is particularly helpful for two reasons. First, compared to conventional maximum likelihood based estimators relying on asymptotic properties, Bayesian estimates provide the benefits of finite-sample results based on the posterior distribution of parameters (Rossi et al.2012), and overcome the global maximum problem of maximum likelihood estimation, which are particularly useful in our case with a small sample size. Second, under the Bayesian estimation framework, the prior distribution can be specified to incorporate unobserved heterogeneity, which can be explained as the spatial heterogeneity in regional tourism growth in our context (Yang and Fik 2014). For example, this heterogeneity can be explained by the demonstration effect arising from the inter-regional competition in tourism growth. Overlooking this potential unobserved heterogeneity may lead to misleading estimation results.

Based on the results from the Granger causality test, we specified the first probit equation to understand what factors facilitate/hinder the transformation of regional tourism expansion into economic growth, and the second probit equation to help identify what factors influence the channeling of regional economic growth into tourism expansion. Therefore, in Equation (1), $y_{1}=$ 1 for the TLG cases, and $y_{1}=0$ otherwise, whereas $y_{2}=1$ for the EDTG cases, and $y_{2}=0$ otherwise. To test research hypotheses 1-6, we incorporated the following independent variables to understand the conditions under which a region can experience TLG and/or EDTG:

- $\ln G D P \_p e r$, the log of GDP per capita (in 2010 prices), which represents the level of economic development (De Vita and Kyaw 2016). This variable is included in the TLG and EDTG equations to test Hypotheses 1 and 5, respectively; 
- $\ln G D P$, the log of GDP (in 10,000 RMB of 2010 prices), which represents the size of the economy of each region. This variable is included in the TLG and EDTG equations to test Hypotheses 2 and 6, respectively;

- Inarea, the log of land area (in $10,000 \mathrm{~km}^{2}$ ), which represents the land area of each region. This variable is included in the TLG equation to test Hypothesis 3;

- $\ln t o u r_{-} G D P$, the $\log$ of international tourism revenue relative to GDP, which represents the level of tourism specialization and tourism dependence (Zuo and Huang 2018). This variable is included in the EDTG equation to test Hypothesis 4.

Since the dependent variables were measured for a period covering multiple years, we used independent variables at the beginning of study period to reasonably alleviate the endogeneity problem in the econometric model (Lesage and Fischer 2008).

\section{EMPIRICAL RESULTS AND DISCUSSION}

\subsection{Results of stationarity, cointegration and causality tests}

The time series plots of the focal variables clearly show that real tourism revenue $(T R)$ and real GDP $(R G D P)$ for all 29 regions rose steadily over the study period (see Figure 1 for some selected regions as examples). Based on this preliminary result, we included a linear trend in the application of unit root tests. We performed the three unit root tests described earlier using initial data for both the $T R$ and $R G D P$ series; if non-stationarity was detected, we performed the tests using first differences data. The three tests rendered the same results in most cases. Due to space constraints, the results are not reported here but are available upon request. At the 0.05 significance level, 27 $T R$ and $28 R G D P$ series are $I(1)$, while only two $T R$ series (i.e., Guangdong and Guangxi) and one $R G D P$ series (i.e., Ningxia) are $I(0)$. Since the maximum order of integration $d_{\max }$ is 1 for all of the focal variables, we were able to examine the presence of cointegration between tourism and economic growth for 29 regions in China.

We estimated the long-run relationship between $T R$ and $R G D P$ using the ARDL bounds test procedure. Given the size of our dataset, we selected a maximum order of 2 and chose appropriate lags based on SBC values (Pesaran and Shin 1998). We report the cointegration test results in Table 1. The null hypothesis of no cointegration is rejected, suggesting a cointegration relationship between $T R$ and $R G D P$ for seven regions (Anhui, Guangdong, Hainan, Inner Mongolia, Ningxia, Shaanxi, and Shanghai) since the calculated $F$ - and $t$-statistics are higher than the upper bound at the 0.05 significance level. The resulting $F$ - and $t$-statistics show the existence of long-run cointegration relationships between $R G D P$ and $T R$ for two provinces (Jiangxi and Shaanxi). The $F$-statistics for Guangdong, Guizhou, Hubei, Inner Mongolia, Shanghai, Xinjiang, and Yunnan are higher than the upper bound at the 0.05 significance level; however, their corresponding $t$-statistics are too small to reject the null hypothesis of no cointegration between $R G D P$ and $T R$ owing to small sample size. 


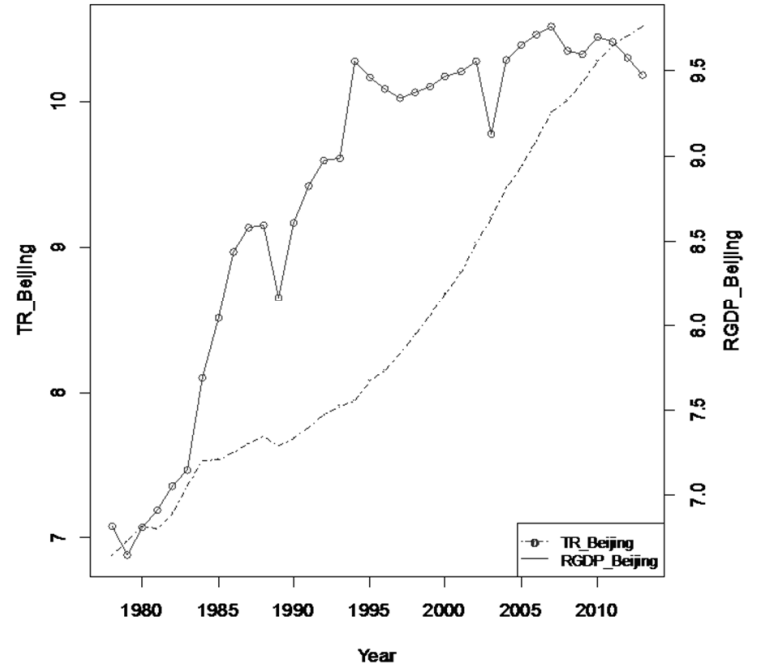

(a) Beijing

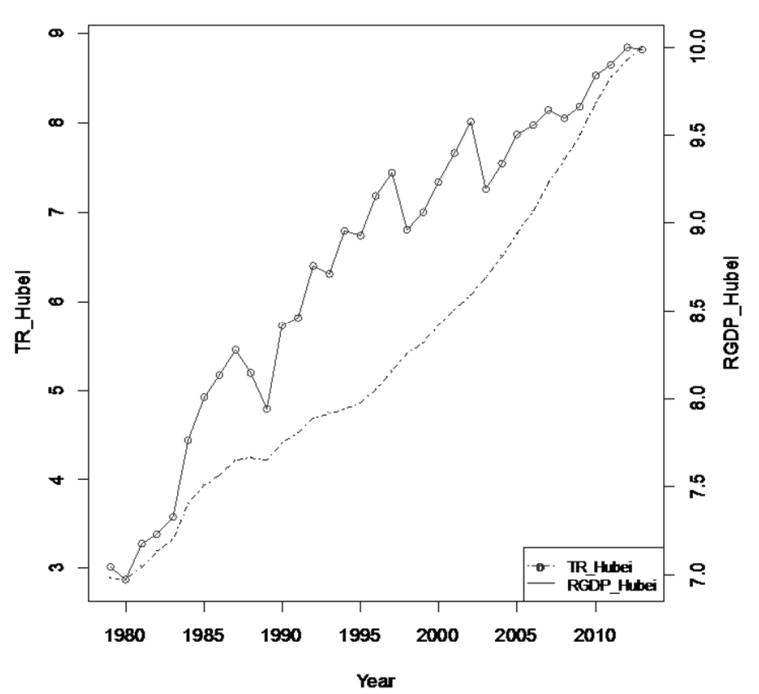

(c) Hubei

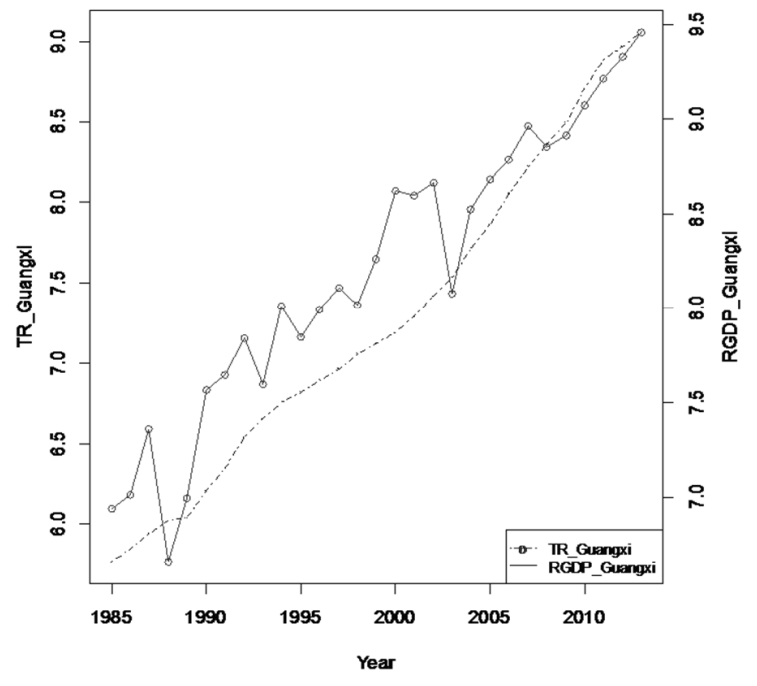

(b) Guangxi

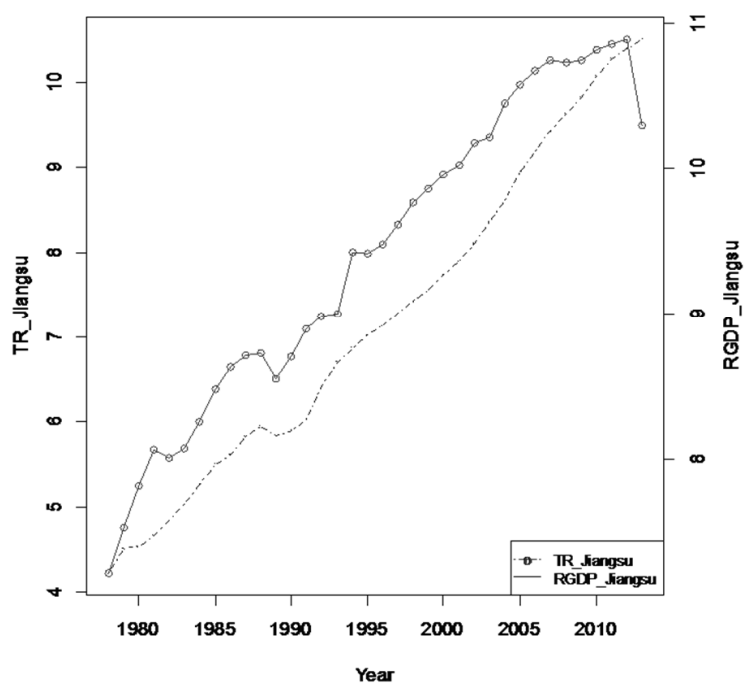

(d) Jiangsu

Figure 1 Plots of real tourism revenue and real GDP of selected provinces

Note: The solid lines represent real tourism revenue (TR), and the dotted lines real GDP (RGDP). 
Table 1 ARDL bounds test and T-Y Granger causality test results

\begin{tabular}{|c|c|c|c|c|c|c|c|c|c|}
\hline \multirow[t]{3}{*}{ Region } & \multirow{3}{*}{$\begin{array}{l}k(k+ \\
\left.d_{\max }\right)\end{array}$} & \multicolumn{4}{|c|}{ T-Y Granger causality tests } & \multicolumn{4}{|c|}{ ARDL bounds tests } \\
\hline & & \multicolumn{2}{|c|}{$H_{0}: R G D P$ does not Granger cause $T R$} & \multicolumn{2}{|c|}{$\begin{array}{l}H_{0}: T R \text { does not Granger cause } \\
R G D P\end{array}$} & \multicolumn{2}{|l|}{ EDTG } & \multicolumn{2}{|l|}{ TLG } \\
\hline & & $\chi^{2}$ & Dummies & $\chi^{2}$ & Dummies & $t$-value & $F$-value & $t$-value & $F$-value \\
\hline Anhui & $1(2)$ & $8.784 * * *$ & D89, D03 & 0.221 & D89, D94 & $-5.387 * * *$ & $15.148 * * *$ & -0.944 & 0.568 \\
\hline Beijing & $1(2)$ & 0.309 & D89, D94, D03 & 2.015 & - & -1.397 & 3.648 & -0.400 & 0.361 \\
\hline Fujian & $1(2)$ & $4.251 * * *$ & D03 & 1.123 & D89 & -2.573 & $11.153 * * *$ & -0.249 & 0.321 \\
\hline Gansu & $2(3)$ & 1.384 & D03, D08 & 3.793 & D89 & -1.910 & 4.283 & -0.699 & 0.323 \\
\hline Guangdong & $4(5)$ & 5.598 & D89 & $13.001 * *$ & D89 & $-8.754 * * *$ & $46.731 * * *$ & -3.341 & $5.929 * *$ \\
\hline Guangxi & $3(4)$ & $17.877 * * *$ & D94, D03 & $11.504 * * *$ & D89 & -3.072 & 4.745 & -1.717 & 3.081 \\
\hline Guizhou & $2(3)$ & 0.534 & D89, D94, D03 & $8.161 * *$ & D89 & -3.440 & 5.990 & -2.082 & $9.480 * *$ \\
\hline Hainan & $5(6)$ & $21.957 * * *$ & D94 & 4.374 & - & $-3.549 * *$ & $6.587 * *$ & -0.364 & 0.483 \\
\hline Hebei & $1(2)$ & 0.010 & D89, D94, D03 & 0.202 & D89, D94 & -0.779 & 1.382 & -1.393 & 1.631 \\
\hline Heilongjiang & $1(2)$ & 5.002 & D94 & 2.232 & - & -0.774 & 5.523 & -1.362 & 0.940 \\
\hline Henan & $2(3)$ & $6.797 * *$ & D94, D03 & 2.215 & D89 & -2.244 & $5.958 * *$ & -0.584 & 0.204 \\
\hline Hubei & $2(3)$ & 3.528 & D89, D03 & $10.204 * * *$ & - & -0.050 & 1.796 & -2.233 & $4.958 * *$ \\
\hline Hunan & $1(2)$ & 1.518 & D03 & 3.771 & D89 & -0.354 & 0.490 & -2.302 & 4.328 \\
\hline $\begin{array}{l}\text { Inner } \\
\text { Mongolia }\end{array}$ & $4(5)$ & $39.537 * * *$ & D89, D03, D08 & $10.079 * *$ & D89, D94 & $-4.582 * * *$ & $10.516^{* * *}$ & -3.230 & $9.510 * *$ \\
\hline Jiangsu & $2(3)$ & $9.037 * *$ & D89 & 0.902 & D89 & -1.984 & $5.690 * *$ & -0.914 & 1.176 \\
\hline Jiangxi & $1(2)$ & 1.636 & D89, D03 & $6.048 * *$ & D89 & -0.346 & 2.072 & $-3.240 * *$ & $7.086^{* *}$ \\
\hline Jilin & $1(2)$ & $8.833 * * *$ & D89, D94, D98, D03 & 0.822 & D89 & -3.412 & $6.221 * *$ & -1.569 & 1.936 \\
\hline Liaoning & $3(4)$ & 1.039 & D89, D94, D03 & 6.933 & - & -1.165 & 2.128 & -2.706 & 3.705 \\
\hline Ningxia & $1(2)$ & 3.723 & D89, D03 & 0.008 & - & $-5.339 * * *$ & $15.147 * * *$ & -2.333 & 2.968 \\
\hline Qinghai & $2(3)$ & 0.982 & D03, D08 & 0.240 & - & -1.778 & 2.334 & -1.006 & 0.947 \\
\hline Shaanxi & $4(5)$ & 0.602 & D89, D94, D03 & $20.489 * * *$ & D94 & $-6.532 * * *$ & $24.458 * * *$ & $-3.801 * *$ & $8.047 * *$ \\
\hline Shandong & $4(5)$ & $10.368 * *$ & D94, D03 & 4.131 & - & -1.984 & $8.391 * * *$ & -2.336 & 2.856 \\
\hline Shanghai & $1(2)$ & 2.551 & D89 & 0.004 & D89 & $-4.317 * * *$ & $9.749 * * *$ & -2.799 & $19.991 * * *$ \\
\hline
\end{tabular}




\section{Table 1 Continued.}

\begin{tabular}{|c|c|c|c|c|c|c|c|c|c|}
\hline \multirow[t]{3}{*}{ Region } & \multirow{3}{*}{$\begin{array}{l}k \quad(k+ \\
\left.d_{\max }\right)\end{array}$} & \multicolumn{4}{|c|}{ T-Y Granger causality tests } & \multicolumn{4}{|c|}{ ARDL bounds tests } \\
\hline & & \multicolumn{2}{|c|}{$H_{0}: R G D P$ does not Granger cause $T R$} & \multicolumn{2}{|c|}{$H_{0}: T R$ does not Granger cause $R G D P$} & \multicolumn{2}{|l|}{ EDTG } & \multicolumn{2}{|l|}{ TLG } \\
\hline & & $\chi^{2}$ & Dummies & $\chi^{2}$ & Dummies & $t$-value & $F$-value & $t$-value & $F$-value \\
\hline Shanxi & $1(2)$ & 1.671 & D89, D94, D03 & $4.222 * *$ & D94 & -1.994 & 1.994 & -0.579 & 0.591 \\
\hline Tianjin & $5(6)$ & 10.901 & - & 3.476 & D89 & -2.711 & 4.513 & -0.773 & 0.339 \\
\hline Tibet & $4(5)$ & 0.762 & D03, D08 & 6.896 & D89 & -2.423 & 3.031 & -2.370 & 4.308 \\
\hline Xinjiang & $1(2)$ & 1.700 & D89, D03 & $4.554 * *$ & D89 & -2.338 & 4.104 & -2.908 & $9.118 * *$ \\
\hline Yunnan & $3(4)$ & 5.231 & D89 & $13.477 * * *$ & D89 & -2.245 & $6.201 * *$ & -0.356 & $6.793 * *$ \\
\hline Zhejiang & $2(3)$ & 1.739 & D89 & 1.941 & D89 & -1.769 & 3.780 & -0.867 & 0.461 \\
\hline
\end{tabular}

Critical value bounds of the $F$ - and $t$-statistics $(k=1)$

\begin{tabular}{lllll}
\hline & & & & \\
\hline & $1 \%$ & $I(1)$ & $I(0)$ & $I(1)$ \\
$F_{\mathrm{C}}$ & $I(0)$ & 7.84 & 4.94 & 5.73 \\
$F_{\mathrm{CT}}$ & 6.84 & 9.63 & 6.56 & 7.30 \\
$t_{\mathrm{C}}$ & 8.74 & -3.82 & -2.86 & -3.22 \\
$t_{\mathrm{CT}}$ & -3.43 & -4.26 & -3.41 & -3.69 \\
\hline
\end{tabular}

Note: (1) ***, and ** indicate rejection of null hypothesis at the $1 \%$ and $5 \%$ significance levels, respectively. (2) The results of lag structure and VAR order are not presented to economize space but they are available from the authors upon request. (3) C: Unrestricted intercept and no trend, CT: Unrestricted intercept and unrestricted trend. (4) D89: a dummy variable for the June Fourth Incident in 1989; D94: a dummy variable for China's RMB exchange rate reform in 1994, D98: a dummy variable for the Asian financial crisis; D03: a dummy variable for the outbreak of Severe acute respiratory syndrome (SARS) in 2003; D08: a dummy variable for the earthquake in Sichuan and visa restrictions prior to the Olympic Games in 2008. 
Table 1 shows the T-Y Granger causality test results in 29 regions. The null hypothesis of " $R G D P$ does not Granger cause $T R$ " is rejected in the cases of Anhui, Fujian, Hainan, Henan, Jiangsu, Jilin, and Shandong at the 0.05 significance level, supporting the EDTG hypothesis in these seven regions. Table 1 also shows that there is strong evidence of unidirectional causality from $T R$ to $R G D P$ at the 0.05 level of significance in eight regions: Guangdong, Guizhou, Hubei, Jiangxi, Shaanxi, Shanxi, Xinjiang, and Yunnan. Therefore, the TLG hypothesis is empirically corroborated in these regions. In addition, a bi-causal relationship is observed between $T R$ and $R G D P$ in the cases of Guangxi and Inner Mongolia, suggesting endogeneity or feedback between international tourism revenues and economic growth in Guangxi and Inner Mongolia. Moreover, no Granger causal relationship between tourism and economic growth is found in any direction in 12 regions (i.e., Beijing, Gansu, Hebei, Heilongjiang, Hunan, Liaoning, Ningxia, Qinghai, Shanghai, Tianjin, Tibet, and Zhejiang), as reported in Table 1.

\subsection{Results of Bayesian bivariate/univariate probit models}

We estimated a series of Bayesian probit models to test the six research hypotheses proposed in Section 2. Following the suggestions from Rossi et al. (2012), we specified the prior distribution of parameters as follows:

$$
\begin{aligned}
& \left(\begin{array}{l}
v_{1} \\
v_{2}
\end{array}\right) \sim N(0,0.01 \cdot \mathbf{I}) \\
& \Sigma \sim \text { inverted Wishart }(4,4 \cdot \mathbf{I})
\end{aligned}
$$

where I is a 2-by-2 identity matrix. We ran 100,000 MCMC draws, and discarded the first 10,000 samples drawn during the burn-in period. The results of these models are presented in Table 2 . In the table, the four columns indicate the posterior mean, standard deviation and the lower and upper bounds of the $95 \%$ posterior density intervals for each parameter, which is the credible region obtained from the posterior as a direct output of the estimation process. Note that the frequentist notion of significance for the coefficient can be evaluated based on whether or not the posterior density set includes 0. Following the suggestions from Koop, Poirier, and Tobias (2007), a parameter is regarded as "significant" if its associated 95\% posterior interval does not include 0 . Furthermore, the term "moderately significant" is used if the $90 \%$ posterior interval does not include 0 . We report the sample proportion of correct prediction as a measure of fit, calculated based on the posterior means of the fitted probabilities (Amisano and Giorgetti, 2013).

We included all six independent variables in the Bayesian bivariate probit model (see Model 1). Four of them have $95 \%$ posterior density intervals that do not include $0: \ln G D P \_p e r, \ln G D P$ and $\ln$ area in the TLG equation, and $\ln G D P \_$per in the EDTG equation. Further, $\ln G D P$ in the EDTG equation has a $90 \%$ posterior interval that does not include 0 . The posterior mean of lnGDP_per is negative in the TLG and EDTG equations; thus Hypotheses 1 and 5 are supported. The results suggest that the regions with less-developed economies were more likely to experience TLG and EDTG during the study period. The positive and significant posterior means of $\ln G D P$ and $\ln$ area (in the TLG equation) lend support to Hypotheses 2, 3 and 6, indicating that the regions with larger economies and covering larger geographic areas were more likely to experience TLG during the study period. However, Hypothesis 4 is not supported. A possible explanation can be that regions with low dependence on tourism growth are usually endowed with less affluent tourism resources, and the lack of resources can hinder further development of tourism. 
Table 2 Results of Bayesian bivariate probit models

\begin{tabular}{|c|c|c|c|c|}
\hline & $\begin{array}{l}\text { Posterior } \\
\text { mean }\end{array}$ & Posterior S.D. & $\begin{array}{l}\text { Lower bound of } 95 \% \\
\text { interval }\end{array}$ & $\begin{array}{l}\text { Upper bound of } 95 \% \\
\text { interval }\end{array}$ \\
\hline \multicolumn{5}{|c|}{ Model 1 (Bayesian bivariate probit) } \\
\hline \multicolumn{5}{|c|}{ TLE Equation } \\
\hline $\ln G D P \_p e r$ & $-3.69 * *$ & 1.59 & -7.32 & -1.20 \\
\hline $\ln G D P$ & $0.94 * *$ & 0.54 & 0.069 & 2.18 \\
\hline $\ln$ area & $1.28 * *$ & 0.60 & 0.35 & 2.67 \\
\hline constant & 1.28 & 4.65 & -7.35 & 11.69 \\
\hline \multicolumn{5}{|c|}{ EDTG Equation } \\
\hline $\ln$ tour_GDP & 0.10 & 0.16 & -0.22 & 0.43 \\
\hline $\ln G D P$ & $0.56 *$ & 0.32 & -0.0062 & 1.24 \\
\hline $\ln G D P \_p e r$ & $-1.31 * *$ & 0.69 & -2.97 & -0.27 \\
\hline constant & 4.63 & 3.82 & -1.09 & 13.77 \\
\hline \multirow[t]{2}{*}{$\sigma$} & $-0.65^{*}$ & 0.28 & -0.97 & 0.05 \\
\hline & $N=29$ & & & \\
\hline \multicolumn{5}{|c|}{ Model 2 (Bayesian bivariate probit) } \\
\hline \multicolumn{5}{|l|}{ TLE Equation } \\
\hline $\ln G D P \_$per & $-3.82 * *$ & 1.63 & -8.57 & -1.26 \\
\hline $\ln G D P$ & $0.95 * *$ & 0.55 & 0.046 & 2.20 \\
\hline $\ln$ area & $1.32 * *$ & 0.62 & 0.33 & 2.76 \\
\hline \multicolumn{5}{|c|}{ EDTG Equation } \\
\hline $\ln G D P$ & $0.51 *$ & 0.30 & -0.045 & 1.16 \\
\hline $\ln G D P_{-}$per & $-1.28 *$ & 0.67 & -2.84 & -0.24 \\
\hline constant & 4.81 & 3.73 & -1.06 & 13.51 \\
\hline \multirow[t]{2}{*}{$\sigma$} & -0.63 & 0.26 & -0.96 & 0.015 \\
\hline & $N=29$ & & & \\
\hline \multicolumn{5}{|c|}{ Model 3 (Bayesian univariate probit) } \\
\hline \multicolumn{5}{|l|}{ TLE Equation } \\
\hline $\ln G D P_{-}$per & $-3.74 * *$ & 1.34 & -6.64 & -1.40 \\
\hline $\ln G D P$ & $0.78 *$ & 0.49 & -0.069 & 1.90 \\
\hline $\ln$ area & $1.26 * *$ & 0.57 & 0.30 & 2.50 \\
\hline constant & $\begin{array}{l}2.75 \\
N=29\end{array}$ & 7.08 & -11.12 & 16.70 \\
\hline \multicolumn{5}{|c|}{ Model 4 (Bayesian univariate probit) } \\
\hline \multicolumn{5}{|c|}{ EDTG Equation } \\
\hline $\ln G D P$ & 0.37 & 0.33 & -0.24 & 1.06 \\
\hline $\ln G D P \_p e r$ & $-1.64 * *$ & 0.78 & -3.31 & -0.27 \\
\hline constant & $\begin{array}{l}7.64^{*} \\
N=29\end{array}$ & 4.44 & -0.21 & 17.04 \\
\hline
\end{tabular}

Note: $* *$ indicates that the $95 \%$ posterior interval does not include 0 , and $*$ indicates that $90 \%$ posterior interval does not include 0 .

In Model 2, we excluded $\ln t o u r_{-} G D P$, which is not significant in Model 1. The Bayesian estimation results suggest that the $95 \%$ posterior density intervals of $\ln G D P \_p e r, \ln G D P$, and lnarea in the TLG equation and $\ln G D P \_$per in the EDTG equation still exclude 0, indicating that they are significant. Moreover, $\ln G D P$ in the EDTG equation is moderately significant. Hence, the results confirm Hypotheses 1, 2, 3 and 5, and provide moderate support for Hypothesis 6.

Since $\sigma$ is estimated to be not significant in Model 2, we also estimated the TLG and EDTG equations separately in univariate Bayesian probit models (Models 3 and 4, respectively). The results are very similar to Model 2, showing that the parameters associated with $\ln G D P \_p e r$ and 
$\ln$ area in the TLG equation and $\ln G D P \_$per in the EDTG equation are significant, whereas those associated with $\ln G D P$ in the TLG equation are moderately significant. However, $\ln G D P$ in the EDTG equation is estimated to be insignificant in Model 4 after removing the interconnectedness specification between TLG and EDTG equations.

\section{CONCLUSIONS}

This study contributes to the debate in the TLG and EDTG literature by further investigating what factors affect the occurrence of TLG or EDTG. Empirical evidence was presented based on rigorous statistical methods including Bayesian inference in a comparable setting of 29 provincial regions in China. In this paper, we started with empirically testing the validity of the TLG and EDTG hypotheses for individual regions using the T-Y Granger causality test. The results indicated a bi-directional causality for two regions (Guangxi and Inner Mongolia), a unidirectional causality from economic growth to international tourism revenue for seven regions, and a reverse causality for eight regions among the 29 provincial regions in China. Different from previous studies, we further employed Bayesian probit models to unveil the key factors explaining the presence of TLG and EDTG. The results suggested that the regions with less-developed economies, larger economies, and covering larger geographic areas are more likely to experience TLG, and those regions less-developed economies are more likely to experience EDTG. It is particularly interesting to note that our results highlighted path dependence in tourism development (Ma and Hassink, 2013), and both EDTG and TLG are more likely to be observed in less developed regions. One potential reason is that with the invested software and hardware in less developed regions to support tourism, these regions' economies are particularly nurturing for tourism economies, and more tourism investment can be budgeted after economic expansion as suggested by EDTG.

This study represents one of the pioneering efforts unveiling region-level factors associated with the occurrences of TLG and EDTG. Although past studies examined some of these factors by categorizing regions/countries into relatively homogenous groups (Lee and Chang 2008) or considering the single threshold effect (Chiu and Yeh 2016), our results provided a list of welldefined factors under rigorous two-step analysis. Unlike previous empirical studies applying panel causality tests to understand the tourism growth - economic expansion nexus across different groups (Lee and Chang 2008), our method is able to highlight individual factors that might be masked in the panel as a group. Also, different from past studies employing (dynamic) panel data model understanding TLG (Zuo and Huang 2018), our method gauged the TLG occurrence based on the first-step individual causality tests instead of the estimated coefficients from the regression, and therefore, its occurrence can be rigorously evaluated.

The findings of the Bayesian bivariate probit models provide further insights into the relationship between tourism and economic growth and provide important policy implications especially for effective resource allocation and policy differentiation given regional characteristics. First, since international tourism development has been found to be an effective strategy for shrinking the income gap across regions, particular policies should be proposed to facilitate TLG, and this strategy should be more promising in less developed areas. For example, to magnify the multiplier effect of tourism through various backward- and forward-linked sectors, inter-sectoral interconnectedness should be strengthened through tactic industrial planning at different levels. In particular, diversifying tourism products can be an efficient way to involve a wider variety of 
economic sectors to participate in producing tourism-related outputs. Second, our results highlighted the important role of the size of economies in facilitating TLG, and economies of scale was found to play a salient role in transferring the tourism growth to economic expansion. Therefore, a single large tourism project with more intense investment is preferred to several segmented small projects to magnify TLG.

Our major results also provide implications for poverty reduction policies. As shown in our results, less economically developed regions are more likely to experience TLG and EDTG. Therefore, in various poverty reduction projects, the government should emphasize the important role of tourism in stimulating local economic growth. Once TLG occurs, such regions are able to better catch up with more developed regions through the spillovers from the tourism industry. Also, an EDTG in these regions will further strengthen the effect of tourism growth by allocating extra benefits from overall economic expansion to tourism investments.

Our results may be tempered by some limitations, which suggest directions for future studies. First, due to data unavailability, we were unable to incorporate other factors that may influence the occurrence of TLG and EDTG, such as tourism resource endowments (Lanza and Pigliaru 2000), environmental sustainability (Pulido-Fernández, Cárdenas-García, and Villanueva-Álvaro 2013), investment climate (Cárdenas-García and Pulido-Fernández 2014) and population characteristics (Sánchez-Rivero and Cárdenas-García 2014). We recommend that researchers consider other explanatory variables and use an international dataset for comparison in the future. Second, an application of the Granger causality approach in which annual data are used to investigate the causal relationship between tourism development and economic growth may suffer from smallsample biases. When longer time series or higher frequency (e.g., quarterly or monthly) data are available, more robust findings are likely to be reached. Third, we focused on detecting linear relationships between tourism development and economic growth in this study. Future efforts should probe possible nonlinear relationships between the two. Lastly, we focused on Chinese regions, and these results might not be generalizable to other countries. Hence, we recommend future empirical analysis on regional data of other countries.

\section{Declaration of Conflicting Interests}

The author(s) declared no potential conflicts of interest with respect to the research, authorship, and/or publication of this article.

\section{Funding}

The author(s) disclosed receipt of the following financial support for the research, authorship, and/or publication of this article: The authors would like to acknowledge the financial support of the National Natural Science Foundation of China (Grant No.: 71503231).

\section{ORCID iD}

Vera Shanshan Lin https://orcid.org/0000-0003-4434-3729

Yang Yang http://orcid.org/0000-0001-9436-964X

Gang Li https://orcid.org/0000-0002-9858-5232 


\section{REFERENCES}

Adamou, A., and S. Clerides. 2010. "Prospects and limits of tourism-led growth: The international evidence." Review of Economic Analysis 3: 287-303.

Akinboade, O. A., and L. A. Braimoh. 2010. "International tourism and economic development in South Africa: A Granger causality test." International Journal of Tourism Research 12 (2):149-163.

Albaladejo Pina, I. P., and M. P. Martínez-García. 2013. "An endogenous growth model of international tourism.” Tourism Economics 19(3): 509-29.

Algieri, B. 2006. "International tourism specialisation of small countries." International Journal of Tourism Research 8(1): 1-12.

Amisano, G., and M. L. Giorgetti. 2013. "Entry into pharmaceutical submarkets: A Bayesian panel probit analysis." Journal of Applied Econometrics 28(4): 667-701.

Antonakakis, N., M. Dragouni, and G. Filis. 2015. "How strong is the linkage between tourism and economic growth in Europe?" Economic Modelling 44: 142-55.

Aslan, A. 2013. "Tourism development and economic growth in the Mediterranean countries: Evidence from panel Granger causality tests." Current Issues in Tourism 17(4): 363-72.

Balaguer, J., and M. Cantavella-Jordá. 2002. "Tourism as a long-run economic growth factor: The Spanish case." Applied Economics 34(7): 877-84.

Belay, S. 2007. "Revealed comparative advantage and competitiveness in services: A study with special emphasis on developing countries." Journal of Economic Studies 34(5): 376-88.

Brau, R., A. Lanza, and F. Pigliaru. 2007. "How fast are small tourism countries growing? Evidence from the data for 1980-2003." Tourism Economics 13(4): 603-14.

Brida, J. G., I. Cortes-Jimenez, and M. Pulina. 2016. "Has the tourism-led growth hypothesis been validated? A literature review." Current Issues in Tourism 19(5): 394-430.

Capone, F., and R. Boix. 2008. "Sources of growth and competitiveness of local tourist production systems: An application to Italy (1991-2001).” Annals of Regional Science 42(1): 209-24.

Cárdenas-García, P. J., and J. I. Pulido-Fernández. 2014. "Does the investment climate determine the transformation of tourism growth into economic development? Tourism Economics 20(4): 669-94.

Cárdenas-García, P. J., and M. Sánchez-Rivero. 2015. "Tourism and economic development: Analysis of geographic features and infrastructure provision." Current Issues in Tourism 18(7): 609-32.

Cárdenas-García, P. J., M. Sánchez-Rivero, and J. I. Pulido-Fernández. 2015. "Does tourism growth influence economic development?" Journal of Travel Research 54(2): 206-21.

Capone, F., and R. Boix. 2008. "Sources of growth and competitiveness of local tourist production systems: An application to Italy (1991-2001)." Annals of Regional Science, 42 (1):209-24.

Castro-Nuño, M., J. A. Molina-Toucedo, and M. P. Pablo-Romero. 2013. "Tourism and GDP: A Metaanalysis of panel data studies." Journal of Travel Research 52(6): 745-58.

Chang, C.-L., T. Khamkaew, and M. McAleer. 2012. "IV estimation of a panel threshold model of tourism specialization and economic development." Tourism Economics 18(1): 5-41.

Chao, C.-C., B. R. Hazari, J.-P. Laffargue, P. M. Sgro, and E. S. H. Yu. 2006. "Tourism, Dutch disease and welfare in an open dynamic economy." Japanese Economic Review 57(4): 501-15.

Chen, L. L., and J. Devereux, 1999. "Tourism and welfare in sub-Saharan Africa: A theoretical analysis." Journal of African Economies 8(2): 209-27.

Chiu, Y. B., and Y. Lung-Tai 2016. "The threshold effects of the tourism-led growth hypothesis: Evidence from a cross-sectional model." Journal of Travel Research 56 (5):625-637.

Claver-Cortés, E., J. F. Molina-Azori'n, and J. Pereira-Moliner. 2007. "Competitiveness in mass tourism." Annals of Tourism Research 34(3): 727-45.

Copeland, B. R. 1991. "Tourism, welfare and de-industrialization in a small open economy." Economica 58(232): 515-29.

Corrie, K., N. Stoeckl, and T. Chaiechi. 2013. "Tourism and economic growth in Australia: An empirical investigation of causal links." Tourism Economics 19(6): 1317-44. 
Cortés-Jiménez, I., J.-J. Nowak, and M. Sahli. 2011. "Mass beach tourism and economic growth: Lessons from Tunisia." Tourism Economics 17(3): 531-47.

Croes, R. 2011. "Measuring and explaining competitiveness in the context of small island destinations." Journal of Travel Research 50(4): 431-42.

Croes, R., and M. Vanegas. 2008. "Cointegration and causality between tourism and poverty reduction." Journal of Travel Research 47(1): 94-103.

de la Mata, T., and C. Llano-Verduras. 2012. "Spatial pattern and domestic tourism: An econometric analysis using inter-regional monetary flows by type of journey." Papers in Regional Science 91(2): 437-70.

del P. Pablo-Romero, M., and J. A. Molina. 2013. "Tourism and economic growth: A review of empirical literature." Tourism Management Perspectives 8: 28-41.

De Vita, G., and K. S. Kyaw. 2016. "Tourism specialization, absorptive capacity, and economic growth." Journal of Travel Research 56 (4):423-35.

Durbarry, R. 2004. "Tourism and economic growth: The case of Mauritius." Tourism Economics 10(4): 389-401.

Edwards, Y. D., and G. M. Allenby. 2003. "Multivariate analysis of multiple response data." Journal of Marketing Research 40(3): 321-34.

Elliott, G., T. J. Rothenberg, and J. H. Stock. 1996. "Efficient tests for an autoregressive unit root." Econometrica 64(4): 813-36.

Eugenio-Martin, J. L., N. Martín-Morales, and M. T. Sinclair. 2008. "The role of economic development in tourism demand." Tourism Economics 14(4): 673-90.

Eugenio-Martín, J. L., N. Martín Morales, and R. Scarpa. 2004. "Tourism and economic growth in Latin American countries: A panel data approach.” FEEM Working Paper No. 26. 2004.

Fawaz, F., M. Rahnama, and B. Stout. 2014. "An empirical refinement of the relationship between tourism and economic growth." Anatolia 25(3): 352-63.

Figini, P., and L. Vici. 2010. "Tourism and growth in a cross section of countries." Tourism Economics 16(4): 789-805.

Granger, C. W. J. 1988. “Causality, cointegration, and control.” Journal of Economic Dynamics and Control 12(2-3): 551-59.

Gunduz, L., and A. Hatemi-J. 2005. "Is the tourism-led growth hypothesis valid for Turkey?" Applied Economics Letters 12(8): 499-504.

He, Z., and K. Maekawa. 2001. “On spurious Granger causality.” Economics Letters 73(3): 307-13.

Huse, M., T. Gustavsen, and S. Almedal. 1998. "Tourism impact comparisons among Norwegian towns." Annals of Tourism Research 25(3): 721-38.

Ivanov, S. H., and C. Webster. 2013. "Tourism's contribution to economic growth: A global analysis for the first decade of the millennium." Tourism Economics 19(3): 477-508.

Katircioglu, S. T. 2009. "Tourism, trade and growth: The case of Cyprus." Applied Economics 41(21): 2741-50.

Khadaroo, J., and B. Seetanah. 2007. "Transport infrastructure and tourism development." Annals of tourism research 34 (4):1021-32.

Kim, H. J., M.-H. Chen, and S. S. Jang. 2006. "Tourism expansion and economic development: The case of Taiwan." Tourism Management 27(5): 925-33.

Koenig-Lewis, N., and E. E. Bischoff. 2005. "Seasonality research: The state of the art." International Journal of Tourism Research 7(4-5): 201-19.

Koop, G., D. J. Poirier, and J. L. Tobias. 2007. Bayesian Econometric Methods. Cambridge: Cambridge University Press.

Lanza, A., and F. Pigliaru. 2000. "Why are tourism countries small and fast-growing?" In Tourism and Sustainable Economic Development edited by A. Fossati and G. Panella, 57-69. New York: Springer.

Lanza, A., P. Temple, and G. Urga. 2003. "The implications of tourism specialisation in the long run: An econometric analysis for 13 OECD economies.” Tourism Management 24(3): 315-21. 
Lee, C.-C., and C.-P. Chang, 2008. "Tourism development and economic growth: A closer look at panels." Tourism Management 29(1): 180-92.

Leones, J., B. Colby, and K. Crandall. 1998. "Tracking expenditures of the elusive nature tourists of southeastern Arizona." Journal of Travel Research 36(3): 56-64.

Lesage, J. P., and M. M. Fischer. 2008. "Spatial growth regressions: Model specification, estimation and interpretation." Spatial Economic Analysis 3(3): 275-304.

Luo, H., Y. Yan, and Y. Yang. 2016. "Can comparative advantage theory explain tourism growth models of Chinese provinces? An inter-provincial study on the contribution of production factors to tourism growth and the comparative advantage of tourism resources in China". Tourism Tribune 31(3): 43-53.

Ma, T., T. Hong, and H. Zhang. 2015. "Tourism spatial spillover effects and urban economic growth." Journal of Business Research 68(1): 71-80.

Ma, M. and R. Hassink. 2013. "An evolutionary perspective on tourism area development". Annals of Tourism Research 41: 89-109.

McKercher, B., A. Chan, and C. Lam. 2008. "The impact of distance on international tourist movements". Journal of Travel Research, 47(2): 208-224.

Narayan, P. K., and S. Narayan. 2005. "Estimating income and price elasticities of imports for Fiji in a cointegration framework." Economic Modelling 22(3): 423-38.

$\mathrm{Ng}$, S., and P. Perron. 2001. "Lag length selection and the construction of unit root tests with good size and power." Econometrica, 69 (6):1519-54.

Nowak, J.-J., and M. Sahli. 2007. "Coastal tourism and 'Dutch disease' in a small island economy." Tourism Economics 13(1): 49-65.

Nowak, J.-J., M. Sahli, and P. M. Sgro. 2003. “Tourism, trade and domestic welfare.” Pacific Economic Review 8(3): 245-58.

Oh, C.-O. 2005. "The contribution of tourism development to economic growth in the Korean economy." Tourism Management 26(1): 39-44.

Parrilla, J. C., A. R. Font, and J. R. Nadal. 2007. "Tourism and long-term growth a Spanish perspective.” Annals of Tourism Research 34(3): 709-26.

Payne, J. E., and A. Mervar. 2010. "The tourism's growth nexus in Croatia.” Tourism Economics 16(4): 1089-94.

Pesaran, M. H., and Y. Shin. 1998. "An autoregressive distributed-lag modelling approach to cointegration analysis." In Econometric Society Monographs edited by S. Strøm, 371-413. Cambridge: Cambridge University Press.

Pesaran, M. H., Y. Shin, and R. J. Smith. 2001. "Bounds testing approaches to the analysis of level relationships." Journal of Applied Econometrics 16(3): 289-326.

Pratt, S. 2011. "Economic linkages and impacts across the TALC." Annals of Tourism Research 38(2): 630-50.

Pulido-Fernández, J. I., P. J. Cárdenas-García, and J. J. Villanueva-Álvaro. 2013. "On the role of environmental sustainability in the transformation of tourism growth into economic development." Environmental Engineering and Management Journal (EEMJ) 12(10): 2009-18.

Ridderstaat, J., R. Croes, and P. Nijkamp. 2014. "Tourism and long-run economic growth in Aruba." International Journal of Tourism Research 16(5): 472-87.

Robles Teigeiro, L., and B. Díaz. 2014. "Estimation of multipliers for the activity of hotels and restaurants." Tourism Management 40, 27-34.

Rossi, P. E., G. M. Allenby, and R. McCulloch. 2012. Bayesian Statistics and Marketing. Chichester: John Wiley and Sons.

Sánchez-Rivero, M., and P. J. Cárdenas-García. 2014. "Population characteristics and the impact of tourism on economic development." Tourism Geographies 16(4): 615-35.

Seetanah, B. 2011. "Assessing the dynamic economic impact of tourism for island economies." Annals of Tourism Research 38(1): 291-308.

Sequeira, T. N., and P. Maçãs Nunes. 2008. "Does tourism influence economic growth? A dynamic panel data approach.” Applied Economics 40(18): 2431-41. 
Shan, J., and K. Wilson. 2001. "Causality between trade and tourism: Empirical evidence from China." Applied Economics Letters 8(4): 279-83.

Tang, C. 2011. "Is the tourism-led growth hypothesis valid for Malaysia? A view from disaggregated tourism markets." International Journal of Tourism Research 13(1): 97-101.

Tang, C.-H., and S. Jang. 2009. "The tourism-economy causality in the United States: A sub-industry level examination.” Tourism Management 30(4): 553-58.

Toda, H. Y., and T. Yamamoto. 1995. "Statistical inference in vector autoregressions with possibly integrated processes." Journal of Econometrics 66(1-2): 225-50.

UNWTO. 2017. Compendium of Tourism Statistics, Data 2011 - 2015 (2017 Edition). Madrid, Spain: World Tourism Organization.

UNWTO. 2018. UNWTO World Tourism Barometer, January 2018 (Vol. 16). Madrid, Spain: World Tourism Organization.

van Leeuwen, E. S., P. Nijkamp, and P. Rietveld. 2009. "A meta-analytic comparison of regional output multipliers at different spatial levels: Economic impacts of tourism." In Advances in Tourism Economics: New Developments edited by Á. Matias, P. Nijkamp and M. Sarmento, 13-33. PhysicaVerlag HD.

Weidenfeld, A. 2013. "Tourism and cross border regional innovation systems." Annals of Tourism Research 42: 191-213.

Wu, D. C., H. Song, and S. Shen. 2017. "New developments in tourism and hotel demand modeling and forecasting", International Journal of Contemporary Hospitality Management 29(1): 507-29.

Yang, Y., and T. Fik. 2014. "Spatial effects in regional tourism growth." Annals of Tourism Research 46: $144-62$.

Yang, Y., and K. K. F. Wong. 2012. "A spatial econometric approach to model spillover effects in tourism flows." Journal of Travel Research 51(6): 768-78.

Zhang, J., and C. Jensen. 2007. "Comparative advantage: Explaining tourism flows." Annals of Tourism Research 34 (1): 223-43.

Zuo, B., and S. Huang. 2018. "Revisiting the Tourism-Led Economic Growth Hypothesis: The Case of China." Journal of Travel Research 57(2): 151-163.

\section{Authors' Biography}

Vera Shanshan Lin, $\mathrm{PhD}$, is an Associate Professor in the School of Management at Zhejiang University. Her research interests include tourism demand modelling and forecasting.

Yang Yang, $\mathrm{PhD}$, is an Assistant Professor in the School of Tourism and Hospitality Management at Temple University. His research interests include business analytics and tourism growth analysis.

Gang Li, PhD, is a Professor of Tourism Economics in the School of Hospitality and Tourism Management at University of Surrey, and an Extraordinary Research Fellow in Tourism Research in Economic Environs \& Society, North-West University, South Africa.

\section{Acknowledgments}

The first author would like to acknowledge the financial support of the National Natural Science Foundation of China (Grant No.: 71503231). 